\title{
A EVOLUÇÃO DA BIBLIOMETRIA E SUA INTERDISCIPLINARIDADE NA PRODUÇÃO CIENTÍFICA BRASILEIRA
}

\author{
THE EVOLUTION OF BIBLIOMETRICS AND ITS NTERDISCIPLINARITY \\ IN BRAZILIAN'S SCIENTIFIC PRODUCTION
}

\author{
José Mauro Gouveia de Medeiros ${ }^{1}$ \\ Maria Albeti Vieira Vitoriano ${ }^{2}$
}

\begin{abstract}
RESUMO
A Bibliometria é uma técnica estatística utilizada para mensurar aspectos da produção acadêmica que contribui para o desenvolvimento da ciência. O objetivo deste artigo é apresentar resultados de pesquisa com base em revisão de literatura sobre esse tema. Contemplam-se as origens desta técnica, principais características e aplicabilidade, a partir de levantamento de trabalhos realizados no Brasil, que foram coletados em determinadas bases de dados. Constata-se a relevância de técnicas bibliométricas apropriadas pelas diversas áreas do conhecimento, o que evidencia seu caráter interdisciplinar. Ressalta-se o importante papel desempenhado pelos periódicos científicos enquanto canais formais para o registro e a difusão da produção científica. Realiza-se uma análise dos Encontros Brasileiros de Bibliometria e Cientometria realizados no Brasil.
\end{abstract}

PALAVRAS-CHAVE: Bibliometria. Comunicação científica. Interdisciplinaridade. Revisão de literatura. Brasil.

\begin{abstract}
Bibliometrics is a statistical technique used to measure aspects of academics works that contributes for the development of science. The objective of this article is to present results based on literature review about this topic. It's contemplate the origins of this technique, main characteristics and them applicability, from work survey conducted in Brazil, which were collected in certain databases. Notes the relevance of appropriate bibliometrics' techniques for different areas of knowledge, which highlights its interdisciplinary character. Emphasizes the important role played by scientific journals as formal channels for the recording and dissemination of scientific production. Is carried out an analysis of Encontros Brasileiros de Bibliometria e Cientometria held in Brazil.
\end{abstract}

KEYWORDS: Bibliometrics. Scientific communication. Interdisciplinarity. Literature review. Brazil.

\section{INTRODUÇÃO}

Neste artigo são apresentados os resultados de levantamento de trabalhos realizados por pesquisadores brasileiros que utilizaram como recurso a Bibliometria para elaboração de pesquisas interdisciplinares, com enfoque naqueles produzidos nas duas últimas décadas.

\footnotetext{
${ }^{1}$ Arquivista, Mestrando em Ciência da Informação pelo Programa de Pós-Graduação em Ciência da Informação da Universidade de Brasília. E-mail: maurogouveiamedeiros@yahoo.com.br

Enviado em: 04/11/2014 - Aceito em: 16/09/2015

${ }^{2}$ Consultora, Doutoranda em Ciência da Informação pelo Programa de Pós-Graduação em Ciência da Informação da Universidade de Brasília. E-mail: albeti@gmail.com

Enviado em: 04/11/2014 - Aceito em: 16/09/2015
} 
Inicialmente, descreve-se a origem desse campo do conhecimento, bem como sua evolução e, em seguida, demonstra-se sua utilização em diversas áreas do conhecimento.

Trata-se de uma área de estudos que "se dedica aos aspectos quantitativos da produção, disseminação e uso da informação registrada" e que faz uso de "métodos matemáticos e estatísticos", podendo "ser classificados segundo as fontes de dados que constituem a base da análise, ou segundo os propósitos ou aplicações dessas mesmas análises” (LARA, 2006).

A utilização de indicadores para mensurar as atividades científicas está cada vez mais presente em debates que permitem estabelecer "as relações entre o avanço da ciência e da tecnologia por um lado e o progresso econômico e social por outro" (MACIAS-CHAPULA, 1998).

\section{METODOLOGIA}

O método aplicado foi o de levantamento bibliográfico, no qual descreveu-se as características de estudos bibliométricos no Brasil, previamente selecionados, bem como sua aplicação em diversas áreas do conhecimento. O levantamento bibliográfico, também conhecido como revisão bibliográfica, trata-se de uma revisão de literatura sobre as teorias fundamentais que embasam o trabalho científico (PIZZANI et al., 2012) e que pode "estar relacionado ao mapeamento do conhecimento e à identificação de fontes de informação científica" (LEITE, 2007).

Foi realizado um levantamento de artigos científicos, publicados entre 2007 e 2014, recuperados nas seguintes bases de dados: "Google Scholar", "Portal de Periódicos da CAPES", biblioteca eletrônica "SciELO" e "Anais do EBBC". Utilizou-se, de forma isolada, os termos "Bibliometria", "Interdisciplinaridade" e "Bibliometria no Brasil" que deveriam estar contidos nos campos de busca.

\section{BIBLIOMETRIA: UMA ABORDAGEM HISTÓRICA}

A utilização de técnicas métricas remonta ao século XIX (ALVARADO, 2007, p. 191). Em 1869, Galton, através de suas experiências, tentou identificar cientistas eminentes usando critérios como a menção dos nomes em bibliografias selecionadas. Campell, em 1896, analisou a dispersão de assuntos em publicações valendo-se de métodos estatísticos (idem, p. 188).

A Bibliometria foi originalmente conhecida como "bibliografia estatística", termo assinalado por E. Wyndham Hulme no ano de 1923, sendo que a nomenclatura contemporânea foi cunhada em 1934 por Paul Otlet em seu "Traité de Documentacion” (ARAÚJO, 2006).

Configura-se como uma área da Ciência da Informação que tem como objetivo analisar a produção científica. É uma ferramenta importante na gestão da informação registrada, disponível para os pesquisadores das diversas áreas do conhecimento humano (ROSTIROLLA, 2014). 
Conforme Guedes e Borschiver (2005), a Bibliometria se fundamenta em três leis, que são consideradas basilares de sua estrutura: Lei de Bradford (produtividade de periódicos), Lei de Lotka (produtividade científica de autores) e Lei de Zipf (frequência de palavras).

Glänzel (2003) identifica três componentes da Bibliometria moderna: para praticantes, que é o domínio da pesquisa básica; para as disciplinas científicas, voltadas para determinados grupos com suas especialidades; e para a gestão em ciência e tecnologia, destinada à avaliação de pesquisas.

De acordo com Mueller (2013), esta ferramenta tem os seguintes objetivos: análise e mapeamento de autorias e co-autorias, colaboração e redes; avaliação e descrição da literatura, impacto e indicadores; produção e produtividade, visibilidade de autores e instituições; e estudos de citação e co-citação.

Os resultados obtidos após uma análise bibliométrica podem abranger os seguintes elementos: I) identificação de tendências e o crescimento do conhecimento em uma área; II) previsão da produtividade e identificação da influência de autores individuais, organizações ou países; III) medição do surgimento de novos temas; IV) análise dos processos de citação e cocitação, além de outros temas (GIUSTI et al., 2011).

A comunicação científica se divide entre canais formais e informais para a divulgação dos resultados de pesquisas científicas (MUELLER, 1994). Os canais informais referem-se à comunicação oral e os canais formais à comunicação escrita, na qual se destaca o periódico científico, o canal mais utilizado pelos cientistas (ALVES, 2011). Todos estes canais subsidiam a realização de estudos métricos, os quais analisam, estatisticamente e sob diversos enfoques, o desempenho, a abrangência, o prestígio e a visibilidade dos trabalhos de pesquisadores e cientistas.

\section{O PAPEL DA COMUNICAÇÃO CIENTÍFICA}

Na visão de Meadows (1999, p. 1), a divulgação das informações científicas depende do "veículo empregado, da natureza das informações e do público-alvo". Ainda segundo o autor, a pesquisa científica pode ser transmitida com a utilização de vários recursos, dentre os quais, se destacam a escrita e a fala.

De acordo com Price (1976, p. 40) o artigo é para o cientista um "meio de comunicar o conhecimento". O periódico científico nasceu com a função de "resumir os livros e fatos da cultura em toda a Europa" (idem) numa tentativa de eliminar a sobrecarga de informações que estava sendo produzida no século XVIII.

O periódico é de fato um dos meios de comunicação mais utilizados para compartilhamento de resultados de pesquisas, dada sua importância, prestígio, abrangência e reconhecimento da comunidade científica. Em parte, esta predileção pode ser atribuída ao fato da "facilidade de publicação, levando a um crescimento expressivo dessa forma de difusão científica" (CÔRTES, 2006, p. 48). 
De acordo com Mueller (2005), existem, na literatura internacional, indícios de que "diferentes áreas dão preferência a canais diferentes para comunicar seus resultados". Em pesquisa realizada com bolsistas brasileiros de Programa de Estágio Pós-Doutoral no Exterior, mantido pela Capes, a autora detectou essa mesma tendência, apesar de afirmar que por algumas limitações não se pode generalizar. De toda forma, o canal de comunicação utilizado pelos cientistas de cada área do saber está condicionado às características do campo de conhecimento e ao interesse dos pesquisadores.

Consideradas um canal formal para registro da produção intelectual, as revistas científicas configuram-se como uma "fonte de avaliação da produção científica de pesquisadores e instituições, por meio de indicadores de citação, autoria, co-autoria e acesso" (GONÇALVES et al., 2006, p. 165).

No que se refere à comunicação escrita, a Bibliometria vem sendo amplamente divulgada no Brasil por meio de artigos publicados em periódicos científicos. Esse comportamento foi ratificado na pesquisa realizada por Urbizagastegui $(2014$, p. 7), na qual constatou que "os meios de comunicação mais utilizados para disseminar os resultados das pesquisas na Bibliometria brasileira são artigos publicados em periódicos acadêmicos". Ainda de acordo com esse autor, o volume de publicação de trabalhos bibliométricos tem crescido a tal ponto que em breve poderá surgir um periódico especializado neste tema.

Outra forma de divulgação de resultado de pesquisas científicas dá-se através de comunicação oral em eventos como encontros, seminários, simpósios, dentre outros.

Os principais eventos no qual são apresentados os trabalhos bibliométricos no Brasil são o Encontro Nacional de Pesquisa em Ciência da Informação - ENANCIB e o Encontro Brasileiro de Bibliometria e Cientometria - EBBC (URBIZAGASTEGUI, 2014).

\section{BIBLIOMETRIA NO BRASIL}

No Brasil, estão se consolidando estudos sobre a Bibliometria, seja como objeto de estudo ou como técnica adotada para realização de pesquisas. Enquanto tema de trabalhos, vem sendo desenvolvidas pesquisas sobre esta ciência desde a década de 1970.

A difusão destes estudos bibliométricos contribuiu para que diversas áreas do saber se apropriassem das técnicas e resultados para analisar alguns aspectos próprios, popularizando, assim, sua adoção enquanto método.

\subsection{Pesquisas sobre a Bibliometria}

O primeiro trabalho sobre Bibliometria, publicado no Brasil, foi a dissertação de mestrado de Gilda Maria Braga, em 1972, intitulada "Relações bibliométricas entre a frente de pesquisa e revisões da literatura: estudo aplicado à Ciência da Informação", apresentada no final do curso de Pós-Graduação em Ciência da Informação do IBICT/UFRJ, tendo como orientador Tefko Saracevic (OLIVEIRA, 1984). 
$\mathrm{Na}$ década de 1980, constatou-se uma falta de interesse mundial pelo tema, que foi retomado a partir dos anos 1990 com o advento do uso do computador, permitindo, assim, uma exploração das metodologias quantitativas (ARAÚJO, 2006).

Um dos indícios que revelam o crescente interesse pela Bibliometria na área de pesquisa está relacionado ao surgimento de algumas subdisciplinas ou subcampos da Bibliometria, (TAGUE-SUTCLIFFE, 1992, tradução nossa) dentre as quais a Cientometria, fundada em 1977, por Tibor Braun (VANTI, 2011).

Enquanto a Bibliometria tem por objeto de estudo livros, documentos, revistas, artigos, autores e usuários, a Cientometria se preocupa com as disciplinas, assuntos, áreas e campos (MACIAS-CHAPULA, 1998).

\subsection{A Bibliometria como método de pesquisa}

A gênese das pesquisas utilizando recursos bibliométricos no Brasil aconteceu na década de 1970. Um dos destaques dessa produção foram os estudos desenvolvidos no hoje conhecido Instituto Brasileiro de Informação Científica e Tecnológica - IBICT (ARAÚJO, 2006). As áreas de Química, Geologia, Doença de Chagas, Esquistossomose e o Cacau foram objeto de estudos a partir da adoção de técnicas bibliométricas (idem).

Na década seguinte, houve um decréscimo da utilização da Bibliometria como técnica para estudos científicos, limitando-se a trabalhos relacionados à Ciência da Informação (MUELLER, 2007). Para a autora, nos anos 1990 retomou-se o desenvolvimento de estudos qualitativos, influenciados pela inovação tecnológica.

Os estudos métricos, nos anos 2000, voltam a figurar como interesse para o desenvolvimento de diversos trabalhos. Além da vocação na Ciência da Informação, destacam-se pesquisas realizadas em áreas como Medicina Tropical, Psicologia, Arquitetura, Urbanismo e Paisagismo, Arquivologia, Comunicação e Educação (MUELLER, 2007).

\section{MARCOS CONTEMPORÂNEOS NO BRASIL}

Através do levantamento realizado para o desenvolvimento desse estudo foi possível identificar produções seminais acerca da Bibliometria no Brasil. Sua importância tem sido evidenciada, atualmente, por meio dos EBBC, já em sua $4^{\text {a }}$ edição, nos quais têm sido suscitadas discussões temáticas interdisciplinares.

Realizada entre os dias 14 e 16/09/2008, no Rio de Janeiro (RJ), a primeira edição deste evento teve como objetivo principal discutir as atuais tendências e as dificuldades da área. As apresentações refletiram, também, a preocupação destes estudos no país. O conteúdo dos trabalhos versaram sobre os seguintes temas: panorama internacional da cientometria; estudos da cientometria na América Latina; aspectos teóricos e metodológicos da cientometria; o caráter multidisciplinar dos estudos cientométricos; estudos sobre os indicadores de tecnologia e 
inovação; as interfaces da cientometria com a Sociologia e a História da Ciência; e, por fim, os indicadores cientométricos para as políticas de gestão em Ciência e Tecnologia.

A segunda edição ocorreu em 2010, nos dias 17 a 19/11, em São Carlos (SP), e visava principalmente promover uma discussão em âmbito nacional sobre os rumos e as tendências das pesquisas nas áreas de interface. No evento, realizaram-se dois mini cursos, um sobre a análise de redes sociais produzidas a partir de Currículos Lattes e outro acerca da estratégia de construção de indicadores de produção científica. Os trabalhos foram categorizados nas modalidades workshop e pôster, divididos da seguinte forma: análise de citação; bases de dados; colaboração; indicadores; periódicos; métodos, técnicas e ferramentas; acesso aberto e publicações eletrônicas; análise de patentes; produtividade e publicações; políticas de pesquisa; sociologia da ciência e cientometria; e webometria.

$\mathrm{Na}$ sua $3^{\text {a }}$ edição, ocorrida entre os dias 27 e 29/08/2012, em Gramado (RS), a preocupação central foi dar continuidade aos estudos sobre esse campo de conhecimento. A programação conteve palestras, mesas redondas, workshops, comunicações e sessões de pôsteres. As temáticas abordavam os seguintes temas: análise de citação; produção e produtividade científica; colaboração; indicadores em Ciência, Tecnologia e Inovação; mapas da ciência; periódicos científicos; métodos, técnicas e ferramentas para estudos bibliométricos e cientométricos; publicações eletrônicas; análise de patentes; bases de dados; políticas de pesquisa; sociologia da ciência; informetria e webometria.

A última edição foi realizada em Recife (PE), de 14 a 16/05/2014, e teve como metas a constituição de uma massa crítica e o estabelecimento de parcerias nos diversos espaços sociais para contribuição do progresso sobre o tema. A programação incluiu mesas redondas, oficinas, palestras e sessões de comunicação. Seus eixos temáticos contemplaram os seguintes temas: periódicos científicos; produção e produtividade científica; métodos, técnicas e ferramentas para estudos bibliométricos e cientométricos; mapas da ciência; análise de citação; bases de dados; publicações eletrônicas; indicadores de ciência e tecnologia; colaboração na ciência; análise de patentes; políticas de pesquisa; informetria e webometria; e sociologia da ciência.

De acordo com a pesquisa de Oliveira e Alves (2014), nota-se a consolidação do evento, que em sua primeira edição teve um simbólico número de 20 participantes, apenas com apresentações orais. Ainda segundo os autores, a $2^{\mathrm{a}}$ e $3^{\mathrm{a}}$ edições juntas reuniram 142 pesquisadores, com apresentações de 71 trabalhos.

No site do $4^{0} \mathrm{EBBC}^{3}$, consta a informação de que a terceira edição contou com a participação de um público médio de 170 pessoas, obtendo a submissão de 115 trabalhos de pesquisadores de todo o país e até de outras nações. Estes dados revelam uma consolidação de pesquisas em Bibliometria no Brasil.

Nos Anais da $4^{\mathrm{a}}$ edição estão disponíveis com acesso aberto 90 trabalhos, conforme apresentados no Quadro 1.

\footnotetext{
${ }^{3}$ Informação disponível em:

<http://www.liber.ufpe.br/conferences/index.php/ebbc4/index/schedConfs/archive>, acesso em 21/06/2014.
} 
QUADRO 1 - Modalidades do $4^{\circ}$ EBBC

\begin{tabular}{|c|c|}
\hline Políticas das Modalidades & Quantidade \\
\hline Produção e produtividade científica & 27 \\
\hline Análise de citação & 13 \\
\hline Métodos, técnicas e ferramentas para estudo bibliométricos e cientométricos & 12 \\
\hline Colaboração na ciência & 8 \\
\hline Bases de dados & 6 \\
\hline Mapas da ciência & 6 \\
\hline Periódicos científicos & 4 \\
\hline Políticas de pesquisa & 4 \\
\hline Análise de patentes & 3 \\
\hline Indicadores de ciência e tecnologia & 3 \\
\hline Publicações eletrônicas & 2 \\
\hline Informetria e webometria & 1 \\
\hline Sociologia da ciência & 1 \\
\hline Total & 90 \\
\hline
\end{tabular}

Fonte: Elaborado pelos autores com dados dos anais do $4^{\circ} \mathrm{EBBC}$.

Observa-se que nas treze modalidades houve uma concentração de trabalhos relacionados aos temas "Produção e Produtividade Científica" correspondente a 24\%, seguidos pelos expressivos índices sobre "Análise de citação" com 12\% e "Métodos, técnicas e ferramentas para estudos bibliométricos e cientométricos" com 11\%. Enquanto isto a modalidade "Informetria e "Webometria" bem como a "Sociologia da Ciência" foram contempladas com uma pesquisa cada uma.

\section{A PRESENÇA DA INTERDISCIPLINARIDADE EM ANÁLISES BIBLIOMÉTRICAS NO BRASIL}

Estudos bibliométricos têm sido realizados em diversas áreas do conhecimento, o que revela um forte indício de interdisciplinaridade e de aplicação prática de seus métodos em pesquisas no Brasil.

Consulta realizada por Rostirolla (2014), na Base de Dados de Teses e Dissertações (BDTD) detectou a presença de 31 teses sobre Bibliometria, entre 1996 e 2013, conforme Quadro 2.

QUADRO 2 - Teses sobre bibliometria

\begin{tabular}{lcc}
\hline \multicolumn{1}{c}{ Área } & Quantidade de teses \% & Número \\
\hline Outras áreas & $35 \%$ & 11 \\
Ciência da informação & $29 \%$ & 9 \\
Educação & $13 \%$ & 4 \\
Comunicação & $13 \%$ & 4 \\
Educação especial & $10 \%$ & 3 \\
\hline Total & $\mathbf{1 0 0 \%}$ & $\mathbf{3 1}$ \\
\hline
\end{tabular}

Fonte: Elaborada pelos autores com dados de ROSTIROLLA (2014). 
De acordo com os dados apresentados, evidencia-se a concentração de teses sobre Bibliometria na área da "Ciência da Informação", com 29\% do total levantado. Vale ressaltar, entretanto, que os $71 \%$ restantes são oriundos de outros campos do saber, o que permite evidenciar uma interface do tema de maneira interdisciplinar, contribuindo para a geração de novos conhecimentos.

No item "Outras áreas" do Quadro 2 estão contempladas numericamente as disciplinas da seguinte forma: Geociências (2), Saúde pública (2), Ciência da computação (1), Ciência e engenharia de materiais (1), Enfermagem (1), Engenharia mecânica (1), Medicina (1), Política científica e tecnológica (1) e Tecnologia nuclear.

Outro indício da interdisciplinaridade aplicada aos estudos bibliométricos pode ser constatado na análise de trabalhos científicos obtidos nas bases de dados "Google Scholar", "Portal de Periódicos da CAPES" e biblioteca eletrônica "SciELO", apresentados, por ordem cronológica, no Quadro 3.

QUADRO 3 - A interdisciplinaridade em pesquisas com técnicas bibliométricas

\begin{tabular}{|c|c|c|c|}
\hline Área & Título do Artigo & Autores & Ano \\
\hline Educação Jesuítica & $\begin{array}{l}\text { Um estudo bibliométrico da produção científica sob } \\
\text { educação jesuítica no Brasil colônia }\end{array}$ & $\begin{array}{l}\text { HAYASHI, Maria Cristina } \\
\text { Piumbato Innocentini; HAYASHI } \\
\text { Carlos Roberto Massao; SILVA, } \\
\text { Márcia Regina da; LIMA, Mayckı } \\
\text { Young de }\end{array}$ & 2007 \\
\hline Psicologia & $\begin{array}{l}\text { Estudo bibliométrico da produção brasileira na } \\
\text { interface da psicologia com espiritualidade- } \\
\text { religiosidade }\end{array}$ & $\begin{array}{l}\text { JARROS, Rafaela Behs; DIAS, } \\
\text { Hericka Zogbi J.; MÜLLER, } \\
\text { Marisa Campio; SOUSA, Paulo } \\
\text { Luis Rosa }\end{array}$ & 2008 \\
\hline Enfermagem & $\begin{array}{l}\text { A produção do conhecimento em enfermagem e } \\
\text { envelhecimento: estudo bibliométrico }\end{array}$ & $\begin{array}{l}\text { RAVELLI, Ana Paula Xavier; } \\
\text { FERNANDES, Gisele Cristina } \\
\text { Mandrini; BARBOSA, Sayonara । } \\
\text { Fátima Faria; SIMÃO, Eunice; } \\
\text { SANTOS, Silvia Maria Azevedo } \\
\text { dos; MEIRELLES, Bettina Horne } \\
\text { Schlindwein }\end{array}$ & 2009 \\
\hline Ensino e Pesquisa & $\begin{array}{l}\text { Ensino e pesquisa em administração: um estudo } \\
\text { bibliométrico de publicações do EnANPAD (2001- } \\
\text { 2008) }\end{array}$ & $\begin{array}{l}\text { LORDSLEEM, Narcísia } \\
\text { Leopoldina Cavalcanti; ARAÚJO } \\
\text { Richard Medeiros; OLIVEIRA, } \\
\text { Bruna } \\
\text { Miyuki Kasuaya de; } \\
\text { ALEXANDRE, Mauro Lemuel dє } \\
\text { Oliveira }\end{array}$ & 2009 \\
\hline Bioética & $\begin{array}{l}\text { Análise bibliométrica dos } 40 \text { anos da produção } \\
\text { científica em bioética no Brasil e no mundo }\end{array}$ & $\begin{array}{l}\text { PIZZANI, Luciana; SILVA, } \\
\text { Rosemary Cristina da; HOSSNE, } \\
\text { William Saad }\end{array}$ & 2010 \\
\hline $\begin{array}{l}\text { Engenharia de } \\
\text { Produção }\end{array}$ & $\begin{array}{l}\text { Sustentabilidade na engenharia de produção: um } \\
\text { estudo bibliométrico de } 2001 \text { a } 2011\end{array}$ & $\begin{array}{l}\text { GIUSTI, Lorenzo José Martins. } \\
\text { CAMPOS, Lucila Maria de Souza } \\
\text { PEIXE, Blênio César Severo; } \\
\text { TRIERWEILLER, Andréa Cristin }\end{array}$ & 2011 \\
\hline Gestão Estratégica & $\begin{array}{l}\text { Análise da produção científica de artigos sobre gest } \\
\text { estratégica: um estudo bibliométrico }\end{array}$ & $\begin{array}{l}\text { TAVARES, Renata da Silva } \\
\text { Cardoso Rocha; KAMIMURA, } \\
\text { Quésia } \\
\text { Postigo; ARAÚJO, Elvira } \\
\text { Aparecida Simões de }\end{array}$ & 2011 \\
\hline $\begin{array}{l}\text { Engenharia de } \\
\text { Produção }\end{array}$ & $\begin{array}{l}\text { Análise bibliométrica da produção científica de } \\
\text { pesquisadores e referências de um periódico da } \\
\text { engenharia de produção }\end{array}$ & ANDRADE, Fabiana Souza de & 2012 \\
\hline
\end{tabular}




\begin{tabular}{|c|c|c|c|}
\hline Área & Título do Artigo & Autores & Ano \\
\hline $\begin{array}{l}\text { Segurança de Estádi } \\
\text { de futebol }\end{array}$ & $\begin{array}{l}\text { Um estudo sobre segurança em estádios de futebol } \\
\text { baseado na análise bibliométrica da literatura } \\
\text { internacional. }\end{array}$ & $\begin{array}{l}\text { ENSSLIN, Leonardo; ENSSLIN, } \\
\text { Sandra Rolim; PACHECO, } \\
\text { Giovanni Cardoso }\end{array}$ & 2012 \\
\hline Ciências contábeis & $\begin{array}{l}\text { Contabilidade ambiental: um estudo } \\
\text { bibliométrico em revistas científicas brasileiras }\end{array}$ & $\begin{array}{l}\text { FREITAS, Débora Pool da Silva; } \\
\text { QUARESMA, Jozi Cristiane da } \\
\text { Costa; SCHMITT, Solimar } \\
\text { Riograndino Zabot; GONÇALVE } \\
\text { Taiane Lemõns; QUINTANA, } \\
\text { Alexandre Costa }\end{array}$ & 2012 \\
\hline $\begin{array}{l}\text { Turismo e } \\
\text { Gastronomia }\end{array}$ & $\begin{array}{l}\text { A relação turismo/gastronomia na produção } \\
\text { acadêmica brasileira: estudo exploratório do } \\
\text { seminário da ANPTUR 2005-2011 }\end{array}$ & $\begin{array}{l}\text { GIMENES, Maria Henriqueta S. } \\
\text { Garcia; MANOSSO, Franciele } \\
\text { Cristina; GINDRI, Clarissa } \\
\text { Brandolff }\end{array}$ & 2012 \\
\hline Enfermagem & $\begin{array}{l}\text { Produção do conhecimento acerca da formação do } \\
\text { enfermeiro: um estudo bibliométrico }\end{array}$ & $\begin{array}{l}\text { LIMA, Margarete Maria de; } \\
\text { ALMEIDA, Alexsandro Barreto; } \\
\text { GIOVANNETTI, Monica de } \\
\text { Oliveira; BACKES, Vania Marli } \\
\text { Schubert; KLOH, Daiana }\end{array}$ & 2012 \\
\hline Violência Conjugal & $\begin{array}{l}\text { Violência conjugal contra o homem: uma análise } \\
\text { bibliométrica }\end{array}$ & $\begin{array}{l}\text { CEZARIO, Ana Cláudia } \\
\text { Ferreira; LOURENÇO, Lélio } \\
\text { Moura }\end{array}$ & 2013 \\
\hline Ensino e Educação & $\begin{array}{l}\text { Casos de ensino no Brasil: análise bibliométrica e } \\
\text { orientações para autores }\end{array}$ & $\begin{array}{l}\text { FARIA, Marina; FIGUEIREDO, } \\
\text { Klebler Fossati }\end{array}$ & 2013 \\
\hline Turismo & $\begin{array}{l}\text { Percepção do residente em relação a turismo e } \\
\text { megaevento: análise bibliométrica de periódicos } \\
\text { internacionais e latino-americanos }\end{array}$ & $\begin{array}{l}\text { MILITO, Marcelo Chiarelli; } \\
\text { MARQUES, Sérgio; } \\
\text { ALEXANDRE, Mauro Lemuel }\end{array}$ & 2013 \\
\hline $\begin{array}{l}\text { Custos em } \\
\text { organizações Públic }\end{array}$ & $\begin{array}{l}\text { Custos em organizações públicas: um estudo } \\
\text { bibliométrico da produção científica }\end{array}$ & $\begin{array}{l}\text { OLIVEIRA, Robson Ramos; } \\
\text { SILVA, Aline Bernardino da; } \\
\text { SILVA, Elvérsio Vital da; } \\
\text { NASCIMENTO, Viviane Mirandi } \\
\text { Silva do }\end{array}$ & 2013 \\
\hline $\begin{array}{l}\text { Gestão Social e } \\
\text { Ambiental }\end{array}$ & $\begin{array}{l}\text { Gestão social e ambiental: um estudo das redes } \\
\text { cognitivas do SEGET e do SEMEAD }\end{array}$ & $\begin{array}{l}\text { OLIVEIRA, Robson Ramos; } \\
\text { SILVA, Erick Araújo da; ALVES } \\
\text { Maria Regina Menezes; VIEIRA, } \\
\text { Sérgio dos Santos }\end{array}$ & 2013 \\
\hline $\begin{array}{l}\text { Governança de } \\
\text { Tecnologia da } \\
\text { Informação }\end{array}$ & $\begin{array}{l}\text { Análise bibliométrica de modelos e frameworks de } \\
\text { governança de TI }\end{array}$ & $\begin{array}{l}\text { SANTOS, Nirian Martins Silveira } \\
\text { dos; OLIVEIRA, Guilherme } \\
\text { Antônio de Sousa }\end{array}$ & 2013 \\
\hline Ciências da saúde & $\begin{array}{l}\text { Avaliação da informação científica em } \\
\text { bibliometria aplicada às ciências da saúde }\end{array}$ & SILVA, Rosemary Cristina & 2013 \\
\hline Agricultura & $\begin{array}{l}\text { Análise bibliométrica dos } 40 \text { anos da produção } \\
\text { científica em bioética no Brasil e no mundo }\end{array}$ & SOUZA, Cláudia Danielle de & 2013 \\
\hline Perícia Contábil & $\begin{array}{l}\text { Uma análise bibliométrica dos artigos científicos en } \\
\text { pericia contábil publicados entre os anos de } 1999 \text { a } \\
2012\end{array}$ & $\begin{array}{l}\text { TAVEIRA, Lis Daiana Bessa; } \\
\text { MEDEIROS, Ayron Wanderley; } \\
\text { CAMARA, Renata Paes de Barro: } \\
\text { MARTINS, Joana Darc Medeiros }\end{array}$ & 2013 \\
\hline Ensino e Educação & $\begin{array}{l}\text { A influência de Paulo Freire no ensino de } \\
\text { ciências e na educação CTS }\end{array}$ & $\begin{array}{l}\text { ZAUITH, Gabriela; HAYASHI, } \\
\text { Maria Cristina Piumbato } \\
\text { Innocentini }\end{array}$ & 2013 \\
\hline Gestão Pública & $\begin{array}{l}\text { Avaliação de desempenho na gestão pública: um } \\
\text { estudo bibliométrico dos trabalhos apresentados nos } \\
\text { anais do EnANPAD entre } 1997 \text { e } 2012\end{array}$ & $\begin{array}{l}\text { PEREIRA, Gênesis Miguel; } \\
\text { GADELHA, Kalyne Amaral Di } \\
\text { Lorenzo; LUCENA, Wenner } \\
\text { Glaucio Lopes }\end{array}$ & 2014 \\
\hline
\end{tabular}

Fonte: Elaborado pelos autores a partir de pesquisa em bases de dados. 
O Quadro 3 revela que muitas áreas do conhecimento tem utilizado instrumentos bibliométricos para explorar suas atividades, buscando obter indicadores e características que poderão ser utilizados para compreensão de alguns de seus aspectos e viabilização de tomada de decisão.

\section{CONSIDERAÇÕES FINAIS}

De acordo com os levantamentos efetuados foi possível obter um panorama do desenvolvimento da Bibliometria, dos primórdios aos recentes usos, e a aplicabilidade de suas técnicas e fundamentos no Brasil.

Observou-se que os primeiros trabalhos no país surgiram na década de 1970, passando por um momento de quase esquecimento na década de 1980. O interesse pela temática foi retomado nos anos 1990, ratificado no século XXI pela realização dos EBBC e pelo crescente número de artigos científicos, teses e dissertações.

Constatou-se, também, que a ampla utilização de métodos e técnicas bibliométricas nos diversos campos do conhecimento deve-se aos avanços tecnológicos que propiciaram uma maior apropriação dos fundamentos da Bibliometria pelos pesquisadores, despertando seu interesse a tal ponto que as pesquisas vem crescendo amplamente a cada ano.

A consolidação da Bibliometria, no Brasil, pode ser evidenciada pelo crescente número de pesquisas que utilizam seus recursos e técnicas para obtenção de resultados que revelem indicadores de produtividade científica. Esta consolidação está firmada, também, pela presença do tema em eventos nacionais da Ciência da Informação e de evento específico que congrega pesquisadores da área.

Os dados coletados evidenciam a forte presença de interdisciplinaridade, tendo em vista que pesquisadores de diferentes áreas científicas realizam estudos bibliométricos.

\section{REFERÊNCIAS}

ALVARADO, R. U. A Bibliometria: história, legitimação e estrutura. In: TOUTAIN, L. M. B. B. (Org.). Para entender a ciência da informação. Salvador: EDUFBA, 2007.

ALVES, L. Informação e os sistemas de comunicação científica na ciência da informação. DataGramaZero, Rio de Janeiro, v. 12, n. 3, jun. 2011.

ARAÚJO, C. A. Bibliometria: evolução histórica e questões atuais. Em Questão, Porto Alegre, v. 12, n.1, p. 11-32, jan./jun. 2006. 
CÔRTES, P. L. Considerações sobre a evolução da ciência e da comunicação científica. In: POBLACION, D. A.; WITTER, G. P.; SILVA, J. F. M. (Org.). Comunicação e produção científica: contexto, indicadores, avaliação. São Paulo: Angellara, 2006.

GIUSTI, L. J. M. et al. Sustentabilidade na engenharia de produção: um estudo bibliiométrico de 2001 a 2011. In: SIMPÓSIO DE ENGENHARIA DE PRODUÇÃO, 18., Anais eletronicos... São Paulo, 2011. Disponível em: <http://www.peteps.com.br/arquivos/4199_XVIII_SIMPEP_Art_903.pdf >. Acesso em: 18 set. 2014.

GLÄNZEL, W. Bibliometrics as a research field: a course on theory and application of bibliometric indicators. Course handouts, 2003. Disponível em: <http://www.cin.ufpe.br/ ajhol/futuro/references/01\%23_Bibliometrics_Module_KUL_BIB LIOMETRICS\%20AS\%20A\%20RESEARCH\%20FIELD.pdf>. Acesso em: 18 jun. 2014.

GONÇALVES, A.; RAMOS, L. M. S. V. C.; CASTRO, R. C. F. Revistas científicas: características, funções e critérios de qualidade. In: POBLACION, Dinah Aguiar; WITTER, G. P.; SILVA, J. F. M. (Org.). Comunicação e produção científica: contexto, indicadores, avaliação. São Paulo: Angellara, 2006.

GUEDES, V. L. S.; BORSCHIVER, S. Bibliometria: uma ferramenta estatística para a gestão da informação e do conhecimento, em sistemas de informação, de comunicação e de avaliação científica e tecnológica. In: ENCONTRO NACIONAL DE CIÊNCIAS DA INFORMAÇÃO, 6, 2005, Salvador. Anais eletrônicos... Salvador, 2005.

Disponível

em: <http://www.feg.unesp.br/ fmarins/seminarios/Material\%20de\%20Leitura/Bibliometria/ Artigo\%20Bibliometria\%20-\%20Ferramenta\%20estat\%EDstica\%20VaniaLSGuedes.pdf >. Acesso em: 29 jun. 2014.

LARA, M. L. G. Glossário: termos e conceitos da área de comunicação e produção cientítica. In: POBLACION, D. A.; WITTER, G. P.; SILVA, J. F. M. (Org.). Comunicação e produção científica: contexto, indicadores, avaliação. São Paulo: Angellara, 2006.

LEITE, F. C. L. Comunicação científica e gestão do conhecimento: enlaces conceituais para fundamentação da gestão do conhecimento no contexto de universidades. Transinformação, Campinas, v. 19, n. 2, p. 139-151, maio/ago. 2007.

MACIAS-CHAPULA, C. A. O papel da informetria e da cientometria e sua perspectiva nacional e internacional. Ciência da Informação, Brasília, v. 27, n. 2, p.134-140, maio/ago. 1998.

MEADOWS, A. J. A comunicação científica. Brasília: Briquet de Lemos, 1999. 
MUELLER, S. P. M. O impacto das tecnologias de informação na geração do artigo científico: tópicos para estudo. Ciência da Informação, Brasília, v. 23, n. 3, set./dez. 1994.

A publicação da ciência: áreas científicas e seus canais preferenciais.

DataGramaZero, Rio de Janeiro, v. 6, n. 1, fev. 2005.

Estudos sobre comunicação e informação científica na ciência da informação. In: ENCONTRO NACIONAL DE PESQUISA EM CIÊNCIA DA INFORMAÇÃO, 8., 2007, Salvador. Anais eletrônicos... Salvador, 2007. Disponível em: <http://enancib.ibict.br/index.php/enancib/viiienancib/paper/viewFile/2956/2083>. Acesso em: 17 jun. 2014.

Estudos métricos da informação em ciência e tecnologia no Brasil realizados sobre a unidade de análise artigos de periódicos. Liinc em Revista, Rio de Janeiro, v. 9, n. 1. p. 6-27, maio 2013. Disponível em: $<$ http://repositorio.unb.br/bitstream/10482/16129/1/ARTIGO EstudosMetricosInformacao.pdf $>$. Acesso em: 17 jun. 2014.

OLIVEIRA, S. M. Aplicações e limitações dos processos bibliométricos. Revista Brasileira de Biblioteconomia e Documentação, São Paulo, v. 17, p. 55-65, jan./jul. 1984.

OLIVEIRA, E. F. T.; ALVES, B. H. Os encontros brasileiros de Bibliometria e cientometria (EBBCS) em foco: análise da produção, temáticas e relações de coautoria normalizadas. In: ENCONTRO BRASILEIRO DE BIBLIOMETRIA E CINETOMETRIA, 4., 2014, Recife. Anais eletrônico... Recife: UFPE, 2014. Disponível em: $<$ http://www.brapci.inf.br/article.php?dd0=0000014364\&dd90=0cedcf5be3>. Acesso em: 19 jun. 2014.

PIZZANI, L. et al. A arte da pesquisa bibliográfica na busca do conhecimento. Revista Digital de Biblioteconomia e Ciência da Informação, Campinas, v, 10, n. 1, p. 53-66, jul./dez. 2012.

PRICE, D. J. S. O desenvolvimento da ciência: análise histórica, filosófica, sociológica e econômica. Rio de Janeiro: Livros Técnicos e Científicos, 1976.

ROSTIROLLA, G. Bibliometria como tema de tese: análise a partir da biblioteca digital de teses e dissertações. In: ENCONTRO BRASILEIRO DE BIBLIOMETRIA E CINETOMETRIA, 4., 2014, Recife. Anais eletrônico... Recife: UFPE, 2014. Disponível em: <http://www.brapci.inf.br/article.php?dd0 $=0000014364 \& d d 90=0$ cedcf5be3>. Acesso em: 19 jun. 2014.

TAGUE-SUTCLIFFE, J. An introduction to informetrics. Information Processing \& Management, Elmsford, v. 28, n. 1, p. 1-3, 1992. 
URBIZAGASTEGUI, R. A Bibliometria, informetria, cienciometria e outras "metrias" no Brasil. In: ENCONTRO BRASILEIRO DE BIBLIOMETRIA E CIENTOMETRIA, 4. Recife, 2014. Anais eletrônico... Disponível em <http://www.brapci.inf.br/ebbc/article.php?dd0=14454\&dd90=e4b1fa80ac>. Acesso em: 29 jun. 2014

VANTI, N. A cientometria revisitada à luz da expansão da ciência, da tecnologia e da inovação. Ponto de Acesso, Salvador, v. 5, n. 3, p. 5-31, dez. 2011.

Como citar este documento:

MEDEIROS, José Mauro Gouveia de; VITORIANO, Maria Albeti Vieira. A evolução da bibliometria e sua interdisciplinaridade na produção científica brasileira. Revista Digital de Biblioteconomia e Ciência da Informação, Campinas, SP, v. 13, n. 3, p. 491-503, set. 2015. ISSN 1678-765X. Disponível em: <http://periodicos. sbu.unicamp.br/ojs/index.php/rdbci/article/view/8635791>. Acesso em: 18 Set. 2015. 